See discussions, stats, and author profiles for this publication at: https://www.researchgate.net/publication/309690585

\title{
The postmodern aesthetic of Chinese online comment cultures
}

Article in Communication and the Public · November 2016

DOI: $10.1177 / 2057047316677839$

1 author:

ค Yizhou Xu

University of Wisconsin-Madison

2 PUBLICATIONS 4 CITATIONS

SEE PROFILE 


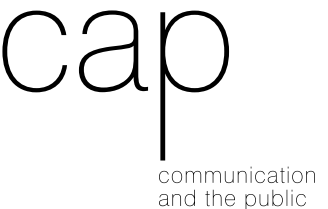

\title{
The postmodern aesthetic of Chinese online comment cultures
}

Communication and the Public 20I6, Vol. I (4) 436-45। (c) The Author(s) 2016 Reprints and permissions: sagepub.co.uk/journalsPermissions.nav DOI: 10.1 I77/2057047316677839 ctp.sagepub.com

(B)SAGE

\section{Yizhou Xu}

University of Wisconsin-Madison, USA

\begin{abstract}
The traditional configuration of content on top and comments on the bottom on most websites often dismiss comments as of secondary importance to content. This article looks at how comment culture(s) in China operate outside of the top-bottom dichotomy where comments are increasingly supplanting content as the main form of consumable media. Through case studies of two types of Chinese comment cultures-gailou culture and danmu culture-l explore how user-generated comments can work to subvert established hierarchies in a highly visible and public manner. I invoke traditional Chinese aesthetic perspectives to visualize the multiple layers of interactions that enable the reconfiguration of the temporal/spatial order contesting the unitary narrative. In doing so, I seek to shed light on not only these distinct modes of commenting practices but also the creation of a new aesthetic of consumption that is inseparable from the formation of the Chinese postmodern subjectivity.
\end{abstract}

\section{Keywords}

Aesthetics, China, online comments, postmodernism, social media

Online comments as a form of user-generated content is just one of the many Web 2.0 collaborative tools adopted by websites, blogs, and wikis to encourage user cooperation and interaction. Usergenerated comments are becoming an important portal for journalists, marketers, and academics to examine online user reactions, behavior, and participation. Western scholarship uses a myriad of terms such as prosumer (producer and consumer), "wikinomics" (Tapscott \& Williams, 2008), "collective intelligence" (Jenkins, 2006; Lévy, 1997), and media convergence to describe this rise of online collaboration and "participatory culture" (Jenkins, 2012c). In 2006, TIME magazine selected "You" as its Person of the Year, where you and I, along with millions of other people, can be empowered by digital media platforms such as Facebook, YouTube, and
Twitter. Yet at the very same time, the article cautioned that Web 2.0 can harness both the powers of collective knowledge and collective stupidity (Grossman, 2006). Such cynicism is not unfounded as the democratizing effect of Web 2.0 has increasingly fallen under the scrutiny from critics and users alike. Andrew Keen (2008) went as far as comparing Web 2.0 to a cult of amateurs who directly threatened the authenticity and integrity of the established cultural gatekeepers. Furthermore, contrary to the constructive roles of social media in enabling user participation, user-generated comments can also

\footnotetext{
Corresponding author:

Yizhou Xu, 2147 Vilas Hall, 82 I University Avenue Madison, WI 53706, USA.

Email: yxu327@wisc.edu
} 
embody destructive behaviors such as "trolling" and "flaming" that thrived under the guise of online anonymity (Phillips, 2015).

The toxic environment of the comment sections on many websites has given rise to the common admonishment of "don't read the comments." Comments are often seen as something to be cast aside and relegated to the "bottom of the internet." Many popular Western sites such as Engadget, Boing Boing, NPR, and the Washington Post have all disabled their comment sections in recent years, while other sites have made extensive efforts to moderate and monitor user comments to foster more civil interactions. In 2013, Google's attempt to moderate the YouTube comment community by integrating real-name Google+ accounts led to an uproar among netizens ${ }^{1}$ that ultimately failed to stem the tide of site's notorious comment culture, and in 2015, Google unlinked public Google+ accounts from YouTube (Horowitz, 2015). Despite extensive moderation and the implementation of CAPTCHA and real-name ID, many sites are still unable to curb the prevalent abuse on the Internet. The disconnect between chaotic commenting practices to that of mass online collaboration necessitates the understanding of the distinction of comment culture within the wider context of participatory culture. Here, I employ the definition of culture from Raymond Williams (1958), who considered culture as the "record of our reactions in thought and feeling, to the changed conditions of our common life" (p. 314). Such reactions to different contexts allows for the mutability of culture or culture(s) in response to social change. Similarly, for John Reagle (2015), "comment is communication, it is social, it is meant to be seen by others and it is reactive" (p. 2). Classifying commenting as a cultural form therefore allows for the diversity of different comment cultures as users react to changing circumstances while rejecting the fixity of a unitary dominant culture. Understanding how comment cultures can exist in diverse mediums helps us contextualize how commenting practices can operate differently across local and global contexts. It also raises questions of how individuals can visibly negotiate, facilitate, and appropriate comments in ways different from the West.
Chinese online culture relating to netizen interactions occupies a contradictory discourse between that of visibility and neglect. Much of recent literature dealing with Chinese online culture has a tendency to focus on case studies of "national Internet events" (Qiang, 2011) such as online reactions to the severe acute respiratory syndrome (SARS) outbreak and the BMW incident (Hung, 2006), viral satiric videos such as "The Bloody Case of a Steamed Bun" (Meng, 2011), and the debate surrounding the Green Dam Youth Escort (Li, 2011; Yang, 2011). However, the emphasis on "online incidents" limits the sphere of comment culture within politicized discourse within the binary confines of censorship and resistance. Focusing on specific online phenomenon fixated on the palpable, exceptional, and obvious cases of resistance too often ignores the nuanced online/ offline interactions among individuals and communities in their everyday lives, as such user comments only become relevant during politicized online contingencies stemming from online or offline events. Reagle suggests that the inherent reactive nature of comments makes it "contextual," yet at the same time also "hypertextual," as messages and meanings circulate and are taken out of context. The ability for comments to breakdown the top-down duplex between content and comment allows for the subversion of dominant narratives. In fact, many Chinese sites have now elevated comments into their own dedicated channels of broadcast as new outlets for mediated content, allowing comments to overtake content as the focus for user engagement. Here, I want to avoid detailing specific "online incidents," but rather I want to look at the formal and aesthetic mechanisms that give rise to different comment cultures. Rather than asking the question of "what does these comments mean?" the focus on aesthetic experiences seeks to address "how does such comments work?" In short, aesthetic analysis can unravel the nuanced ways comment cultures undermine the established textual and spatial authority, which in turn can provide a greater understanding toward the broader social shifts within the realms of cultural production and reception. Through case studies of two types of Chinese commenting practices - gailou culture on the web portal NetEase and danmu culture on the video site BiliBili-I seek to relate traditional 
Chinese aesthetic perspectives of poetry and art with that of postmodern aesthetics of depthlessness and superficiality. In doing so, I aim to contextualize the multiple layers of online interactions among Chinese netizens that enable the reorientation and reconfiguration of power structures between that of producer/ consumer, content/reactions, and media/audience that are different from the Western Experience. My selection of these two case studies relating to the distinct comment cultures on NetEase and BiliBili underscores not merely different types of commenting practices but the evolution of comment culture from symmetrical (top-down) to asymmetrical (layered) modes of online consumption. Both NetEase and BiliBili, while having uncommon provenance, share the same logical progression toward an aesthetic of postmodern consumption. Therefore, both case studies must be read together to help situate not only the status of Chinese comment cultures today but also where it is headed.

\section{Postmodernism and aesthetics of the everyday}

The theories of postmodernism are particularly attractive because it can both challenge the dominant narratives of Western modernity and open up new fissures for the interpolation of new narratives and perspectives. Postmodern theory enables the understanding of radically different forms of consumption outside existing media power structures. The ambiguity of the term also leads to divergent interpretations of the postmodern experience, especially in the context of the radical socioeconomic transformation of globalization. Jean-François Lyotard (1984) in his magnum opus The Postmodern Condition: A Report on Knowledge voiced skepticism toward the emancipatory aims of the modernist project, and instead advocated the absolute incredulity toward the grand narrative in order to wage a war on "totality." Lyotard's focus on aesthetics situates his critique of the referent and he credits innovations in communication technologies such as cinema and photography as new mediums of narrative that can challenge the objective rational reality. In contrast to Lyotard, neoMarxist theorist David Harvey (1989) places postmodernity within the context of political economy in relation to the reconfigurations of global capital where the condition of the postmodernity ought to be understood as the transition between Fordist and flexible modes of capital accumulation. Expanding upon Harvey, Fredric Jameson (1992) believes postmodernism is part of cultural logic situated within the rise of consumer society associated with late capitalism. In short, postmodernism in the cultural context can be summed up as "the effacement of the boundary between art and everyday life, the collapse of the distinction between high art and mass/ popular culture, a general stylistic promiscuity, and playful mixing of codes" (Featherstone, 2007, p. 7). More pertinent, however, is the consensus that postmodernity does not represent a complete break from modernity, as the prefix "post" would suggest, but as a constant shift in "surface appearance" as opposed to radical change (Harvey, p. vii). Likewise, Lyotard expressed that "postmodernism thus understood is not modernism at its end but in the nascent state, and this state is constant" (Lyotard, 1984, p. 73). In other words, the precondition for the postmodern experience opens up the opportunities to offset the universalizing notions of Western modernity and allows for the potentials for multiple, hybrid, or coeval modernities.

Mike Featherstone (2007) considers that China and Japan can provide an alternative to the Westerncentric genealogy of modernity. Particularly, the early developments of consumer culture, public spheres, and global trade in Ming China and Edo Japan present a sort of a "proto-modernity" that existed prior to the influx of Western modernization. Traditional Chinese aesthetic practices such as poetry and painting are considered the "art of the living" where everyday artistic production in China has historically been tied to the political and social aspirations of the public literati (Li, 2009, p. x). Likewise, Japanese $z a$ arts such as poetry and tea ceremonies that "emphasize upon aesthetic perceptions, civility and identity-switching are contrasted to Habermasian theory of the bourgeois public sphere's more overt political function as a key outcome of European modernity" (Featherstone, 2007, p. 149). Both instances question the grand narrative of the creation of the emancipatory and rational modern subject and both present 
possibilities for multiple trajectories toward the modernization project. The implications of this in the postmodern context are the ability to critique European modernity vis-a-vis alternate forms of narrative and knowledge creation. This ability to view the world in nonsynchronous temporalities recalls what Chakrabarty (2000/2009) considers the "two histories of capital"-history 1 "posited by capital" and history 2 that exists within, but never wholly subsumed by capital (p. 65). Similarly, the revival of guoxue (national learning) in contemporary China reflects the shift away from both the socialist modernity of the past and market capitalism of the present, where "tradition now appears as a means to transcend the modern" (Dirlik \& Zhang, 2000, p. 4). This also echoes Lyotard's (1984) notion that "a work can become modern only if it is first postmodern," meaning that the very root of modernity can be transplanted by societies and cultures that may otherwise be incommensurable with Western modernity. In sum, the rejection of the grand narrative betrays two distinct interpretations that are particularly useful in explaining gailou and danmu as postmodern aesthetic practices. First, the idea of the grand narrative (or metanarrative) is rooted in the totalizing forces of Western cultural hegemony tracing back to the project of the enlightenment; hence, the shift away from the metanarrative directly challenges Western-centric views of modernization project while opening upon alternate narratives across different global cultures. Second, the disdain toward the grand narrative is inherently anti-authoritarian in nature and, in the case of China, directly subverts oppressive stateled narratives. Finally, the emphasis of postmodernism as an aesthetic movement brings the debate back to the question of culture and the primacy of our mundane day-to-day experiences over that of the rigid structures of the economic base.

The cultural turn in postmodernism helps delineate the roles of our mundane everyday reactions, utterances, and feedback in the formation of online comment cultures and how such online user-mediated content works in disrupting the boundaries between content and consumption. Here, the aestheticization of the everyday life is regarded by many cultural theorists as the very embodiment of the postmodern experience (Featherstone, 2007; Fiske, 1989/2010; Maffesoli, 1996). While the meaning of aesthetics in Western philosophy has long been used to inquire about our essentialist interpretations of beauty and taste, in East Asian societies, aesthetics often encompasses a way of life that is directly linked to people's everyday experiences. Understanding how Chinese aesthetics differ from the West is the key to understand the popularity of online comments. I draw upon Mikhail Bakhtin's (1990) definition of aesthetics as a "form of embodying lived experience" (p. xl), that aesthetics exists as a type of activity that the viewer or the readership must participate in and against. By contextualizing aesthetics as an actionable activity, we can unravel how the interactive mediums of online comments work to contest the definitions of authorship and static nature of texts. Likewise, Lyotard's concept of the postmodern aesthetics as "[putting] forward the unpresentable in presentation itself" (Lyotard, 1984, p. 81) is a useful visualization of the imbrication of comments over that of actual content, and that the consumption of comments is supplanting actual content as forms of consumable media. The valorization of comments in Chinese online culture stands in contrast with common rejoinder "don't read the comments!" that often appears on Western sites. The ugly, toxic, and inflammatory nature of comments left many with the impression that comments should be avoided or relegated to the "bottom of the internet" (Reagle, 2015). But in the case of Chinese online comment cultures, the "unpresentable" aspect of comments is imbedded within the presentation itself, creating a new aesthetic that embraces the irreverent and carnivalesque aspect of online interactions. Gailou and danmu comments thus embody the aesthetic of the postmodern in that net users are increasingly disinterested in the metanarrative (content) and instead become obsessed with multiple small narratives (comments). In other words, the actual meaning of the comments becomes secondary to the actual user experiences of commenting, especially in the context of the disregard for the referent and the focus on the surface and superficial aspect of consumption. 


\section{Comments as content: the verses of resistance}

In late 2012, one of the most popular Chinese online portal NetEase underwent a major redesign that introduced gentie (NetEase Comments), a site dedicated to the comment section from news articles. Founded in 1997, NetEase has evolved from being one of the largest online portals in China into a multimedia service provider spanning gaming, news, software, e-commerce, and mobile products. The origins of NetEase can be traced back to the popularity of the bulletin-board systems, or BBS forum communities, that were once the central space for online activism (Yang, 2009). The early development of BBS among students in major Chinese universities was crucial in shaping the development of Chinese online culture as a whole. Whether it is the rise of blogging and citizen media online (Guo, 2012; MacKinnon, 2008), or the playful culture of parodies and e'gao (Gong \& Yang, 2010; Link, Madsen, \& Pickowicz, 2013), or the contentious politics of online activism (Yang, 2009), it can all be traced back to Chinese BBS communities. The introduction of gentie came at a time when traditional web portals were reinventing themselves in the wake of the decline of the BBS and the rise of web 2.0 platforms such as Weibo. Claiming to provide the content with the "most attitude," NetEase provides critical, often edgy content with the aims of fostering user interaction, a model quickly copied by other rival sites such as Tencent that also introduced its own version of gentie, Tencent niuping, in 2013. Some NetEase users even claimed that "they came not to read the news, but instead the comments." Much like embedded tweets, NetEase gentie showcases the most upvoted comments in a given news article outside the context of the article itself. Oftentimes entire blocks of comments would be uprooted from the comment section and placed on a separate site showing user interactions, where comments are consumed as content by net users. These comments can take the form of satirical verses, jokes, one-liners, slogans, ASCII art, short stories, song lyrics, quotes, and idioms, among others. Perry Link and Kate Zhou (2001) classify some of these as shunkouliu or rhythmic phrases that were popular forms of satire since the 1950 s and have since evolved into popular forms of expressions on Chinese Internet forums.

This transformation of comments into content is not just media companies capitalizing on user-generated content but also divulges the inherent politics of verticality prevalent in Chinese online comment culture. The top-bottom configuration between content and comments has always been a space for contestation by netizens. BBS communities like all online forums are often seen as open spaces for discussion and deliberation, yet its inherent structure remains top-down and hierarchical. All BBS forums share the similar "tree-like structure" (Holtz, Kronberger, \& Wagner, 2012) composed of threads (tiezi) that serve as different topics for users to post comments for discussion. This structure can be seen in nearly every online medium that allows for comments, from Weibo to Youku videos to even Taobao reviews (Chinese equivalent of Twitter, YouTube, and eBay, respectively); the top-down dichotomy between content and comment remains a persistent feature of the Chinese social media landscape. This vertical configuration of online content is even more obvious in the Chinese context. The original author (poster) of a thread in any Chinese BBS is referred to as louzhu, or "tower master," as a metaphor for the stratified nature of the BBS system where the tower master occupies the dual position as both the owner of the thread and the author of the text. In addition, Chinese netizens who were quick to respond to the thread often post "first floor" (yilou) or "second floor" (er'lou) in lieu of "first!" or "second!" responses commonly found on English language sites. These early comments stipulate a "first-mover advantage" (Reagle, 2015, p. 151) where net users compete for attention, while for the Chinese online community, it is the means by which netizens assert their claims over online spaces. NetEase users, for example, developed a commenting culture known as "gailou" or "tower building/construction" to refer to the layering of comments on top of one another as netizens quote, repost, and repurpose content and other comments. The result is not only visually impressive, with stacks of comments occupying the entire pages at a time (Figure 1), but it also signifies the direct appropriation of content by comments. The use of 


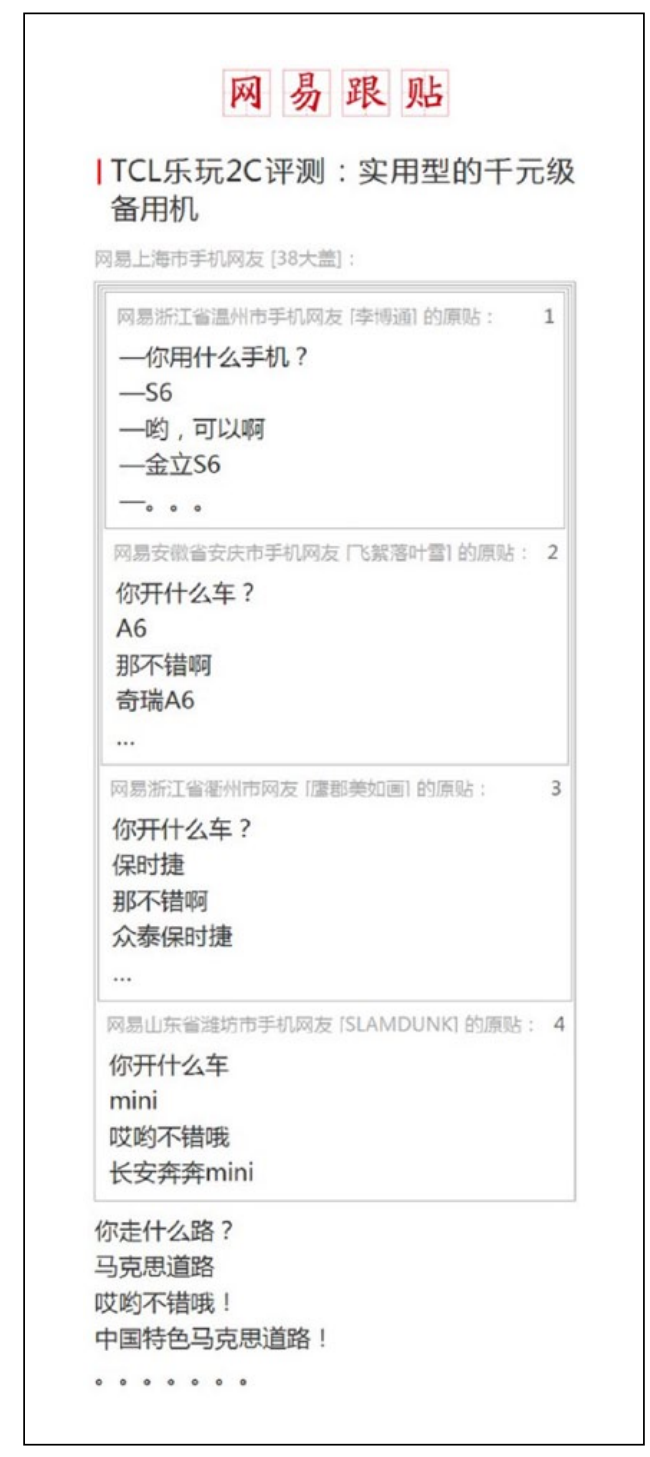

Figure I. An example of gailou culture on NetEase gentie as users engage in playful dueling of verses. Here, the comments are the main content with the original post linked on top. Note the stratified nature of the comments with the corresponding "floor numbers."

gailou supplants the roles of the louzhu (tower master) as netizens build up the layers of comments on top of the foundations of original content.

The popularity of gailou culture as a subversive form is a reflection of the traditional aesthetics of Chinese poetry. The literary method of shihua (talks on poetry) is a classic form of critical practice that was reintroduced by modern literary scholars such as Wang Guowei as the basis for modern Chinese criticism. Like online comments, shihua exists as a form of commentary that is made up of "textual fragments-notes, observations, thoughts, or anecdotes - that [are] seemingly jotted down in a casual manner" (Tong \& Zhou, 2002, p. 157). While shihua as a traditional form of criticism is confined to privileged circles of the Confucian elite, its adaptation as modern criticism after May Fourth divulged a process in which the critic must be relocated from a private realm to a public one, from the realm of aesthetic to the realm of action, a process in which the critic must be transmuted into a modern public intellectual. (p. 163) Thus, modern poetic criticism contributes to the collective critical knowledge enabling the formation of the modern Chinese subject. Moreover, traditional poetic aesthetics also extend to the importance of poetic form. The pervasive use of parallelism and couplets in Chinese traditional poetic structure (Liu, 1966, p. 146) gives meaning to the stratified expressions of online comment culture. The binary composition of the Chinese couplets (duilian) in the form of two antithetical verses betrays the inherent dialectical tensions in Chinese poetry. The parallel construction of couplets in this regard encourages reproduction and mimicry, as the first verse in a couplet opens up the spaces for response, imitation, and circulation, whereas the antithetical nature of couplets also encourages debates, participation, and collaboration. Many netizens engage in dueling duilian as a form of a battle of wits, where each user-generated verse attempts to outdo the preceding verse in the duilian, leading to a cascade of comments that occupies the whole page (Figure 2). Here, the louzhu's (tower master's) function is diminished as the gailou comments replace the original post as the foci for debate. The use of poetic games and contests during informal gathering was an important element of traditional Chinese sociality that serves to promote interpersonal relationships among the literary elite (Hawes, 2006, p. 3).

Patricia Thornton (2002a) considers traditional couplets as a "valuable window into the world of contentious Chinese politics from the perspective of 


\section{1.雾霧基本靠吹 Smog basically requires [blowing] wind

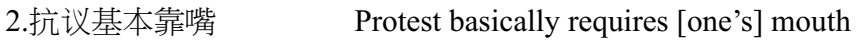

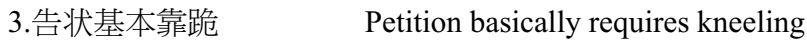 \\ 4.发展基本靠税 \\ Development basically requires taxation \\ 5.真相基本靠黑 \\ Truth basically requires satire \\ 6.民愿基本靠压 \\ People's will basically require oppression \\ 7.收入基本靠灰 \\ Income basically requires illegal [means] \\ 8.工作基本靠混 \\ Work basically requires wasting time \\ 9. 开发基本靠毁 \\ Development basically requires destruction}

Figure 2. A sample gailou (tower construction) comment from an article regarding the pollution in Beijing where netizens react to the government's clean-up policies with ridicule.

participants themselves" (p. 3) and that couplets had existed as a popular form of collective protest in the Republican Era. Chinese couplets are historically used during special occasions such as weddings, anniversaries, and notably during the Spring Festival, when it is known as chunlian or spring couplets (Thornton, 2002b). These traditional Chinese couplets generally manifest in the form of menlian or door couplets that are hung vertically along the side of doorways. Hence, couplets, unlike many other literary genres, are inherently designed for open consumption in public spaces. Thornton notes that unlike James Scott's (1990) notion of the "hidden transcript," couplets are often displayed outside private residences and in the public view. In doing so, it not only openly challenges the established dominant order but also occupies a highly visible space for contention. Gailou culture thus represents the virtual manifestation of traditional couplets that communicates a uniquely Chinese ritual of contention that remains relevant online today. More importantly, couplets as part of gailou culture reveal the hypertextual nature of comments in that NetEase gentie exists as a medium for netizens to respond to one another as opposed to the actual content or news piece. In 2010, the Southern People Weekly magazine published a list of the 100 best things in life of the past decade, and "gailou culture" was included as the embodiment of Chinese netizens' collective intelligence (Jiang, 2010). Similarly, both Jenkins and Lévy used the term collective intelligence to describe the culture of participation where users come together to collaborate to produce new forms of knowledge around shared interests. In 2015 alone, NetEase gentie had accumulated over 1 billion comments from over 142 million registered users (NetEase, 2015). This valorization of comment culture in Chinese online media presents an interesting departure from Western sites, many of which have deliberately limited and restricted comments to curtail vulgar and hateful speech. On sites such as CNN, The New York Times, or the Huffington Post, to have a separate site showcasing the comment section would otherwise be unthinkable.

How then do we explain the active promotion and appropriation of user comments on the Chinese Internet? Heather Inwood (2014) outlines the historical transition of Chinese poetry toward that of the "live scene" (xianchang) that emphasizes on "fleeting moments rather than big schemes and grand narratives, and of the increasingly permeable boundaries between participant and observer, performer and audience, author and reader" (p. 15). For Inwood, "live scene" stresses on "presence, liveness and participation" that are often seen in online interactions (p. 19). The liminal interplay between "live scene" and the state-sponsored poetry scene is indicative of the discontinuity and incongruity within China's transition from postsocialist to neoliberal practices. The shift toward discourses set on realism, 
authenticity, and immediacy is prevalent in Chinese aesthetic genres such as avant-garde documentary, music, cinema, and literature in the 1990s. Thus, live scene discourse runs counter to that of official discourse as forms resistance against established discursive authority. The notion of the live scene mirrors Guobin Yang's conception of the "playful and prosaic styles" in digital activism as a move away from the "heroic" grand narrative toward that of the age of online contention and irreverence (Yang, 2009). This also contributes to what Jameson considers the "weakening of historicity" (Jameson, 1992, p. 6) that reflects the discontinuity of time and the decoupling of signifiers from the metanarrative. The gailou culture of user-generated comments transplanting original content reflects this yearning for the present moment. For instance, each day NetEase gentie broadcast a segment on Internet radio called the "Pantheon of Gentie" (gentie fengshenbang) that collects the best comments of the day which are read aloud by a host alongside the original news piece (NetEase, 2015). By elevating static texts into a live format, it not only engenders a new visceral medium of interaction but also helps convey a form authenticity deeply rooted in the subjectivities of the everyday life. As the next case study will demonstrate, this perception of liveness and revolution of the grand narrative are keys to understand the roles of comment cultures in contributing to the postmodern aesthetic of consumption.

\section{Danmu: Chinese perspective of online visual aesthetics}

Danmu, literally meaning "bullet curtain," is used to describe the visual wall of comments that flies pass the video as viewers engage, react, and participate among one another in real-time. This effect of imbricated flow of comments creates a sense of liveness that enables the meshing of time and space which allows for the perceptions of shared experiences among the audience. Unlike YouTube, where the comment section is placed under the video or adjacent to the video in the case of live streaming sites like Twitch, danmu comments on the popular video site BiliBili are superimposed on top of the video much like subtitles or captions. Similar to closed captions, danmu comments can serve the informative purpose of providing supplementary content to the video (e.g. translations and expositions). But unlike closed captions, danmu culture deliberately injects netizen comments and reactions on top of the actual video content. In doing so, netizens directly appropriate the original content by occupying and disrupting the visual flow of the video. For instance, during the viewing of horror films, viewers would often comment "warning ahead!" (qian fang gao neng) to notify other viewers of frightening scenes. Moreover, during potentially disturbing or offensive scenes, danmu comments would often fill the entire screen blocking off the video in an effort to shield other viewers. Of course, danmu can also be turned off within the video player at any time, but the existence of danmu comments is one of the primary reasons for the popularity of BiliBili among Chinese youths. BiliBili was founded in 2010 imitating the success of AcFun, another popular video site known for its danmu commenting system, but has now overtook AcFun as the most popular danmu site in China. With an estimated active daily user base of nearly 5 million each, both AcFun and BiliBili have since shed their subcultural roots and embraced the mainstream. In 2015, Alibaba, the owner of China's largest video portal Youku/Tudou (Chinese equivalent of YouTube), announced a US\$7.8 million investment in AcFun, while Tencent, one of China's largest online companies, is rumored to invest in BiliBili, a site with an estimated net worth of over US\$1 billion (NetEase, 2015). A recent study detailing the user base of BiliBili over the course of 6 years showed that over $75 \%$ of all registered users are born after 1990 (Qian, 2015), which suggests sites like BiliBili have become the incubator for online youth culture as a whole. Chen Rui, the CEO of BiliBili, states in an interview with Shanghai Daily, "The only difference between subculture and mainstream culture is whether its audience has a voice in society" (Shuang, 2015). Hence, the success of AcFun and BiliBili is precisely because of the active promotion of danmu culture that glorifies real-time user interaction via live comments, thereby giving "voice" to its audience.

As a testament to its increasing influence, danmu comment overlays from BiliBili would also be adopted by mainstream Chinese video sites such as 
Tudou, Baidu, and Tencent Video. In 2014, The New York Times reported that the Chinese blockbuster film Tiny Times 3 became the first movie to incorporate real-time danmu in the form of viewer text messages during a limited theatrical screening. Much like the dueling verses inspired by traditional door couplets in gailou culture, the public consumption of danmu comments highlights the emergence of an open medium of interaction, as viewers simultaneously engage with one another by projecting their own thoughts, opinions, complaints, and jokes on to the big screen from the smaller screens of their smartphones. The transplanting of this online comment culture into the offline world demonstrates the desire for presence and liveness on the part of the audience that manifests itself in a highly visible public medium. The article goes on to quote He Ping, the former secretary general of the China Film Director's Association, who voiced concerns that the "popularization of 'bullet screens' may subvert the aesthetic intentions of the filmmakers" (Qin, 2014). In this regard, danmu culture directly challenges the original content by supplanting its authority through the playful banter of online user interactions. How does this seemingly intrusive and disruptive comment culture emerge and gain popularity among Chinese netizens? On the practical level, due to the initial focus on Japanese anime and manga subcultures, BiliBili required a dedicated fansub community that can help translate overseas content (often from Japan) into Chinese. Danmu sites like BiliBili are dominated by video categories such as anime, music, gaming, tech, entertainment, movies, and TV, where much of the content are sourced from abroad that necessitates subtitles, which danmu culture is a big part of. Diaz-Cintas and Sánchez (2006) in their analysis of fansub groups describe the unconventional use of fan-generated subtitle captions that incorporate "certain cultural referents such as the names of places, traditions and other celebrations are explained by using translator's notes and glosses." Unlike conventional subtitles, which are placed on the bottom of the video and often "pass unnoticed to the viewer," fansubs provide additional exposition and background information in a highly visible manner. The unconventional nature of fansubs allows it to break free of the temporal/spatial confines of closed caption subtitles where it often uses bright colors, different fonts, and different positions on the screen to convey the message (Figures 3 and 4). Many of the danmu comments act as fansubs that involve simultaneous viewer collaboration to provide translations to foreign content. In the context of danmu culture, Chinese fansubbers are able to "created their own poetics" (Cai, 2015) by rewriting and repurposing translated texts with their own brands of humor, satire, and creativity.

The use of subtitles as tools for humor and entertainments as opposed to its original purpose of providing visual aid to those with disabilities can be frequently seen on Asian broadcast television programs. The use of open caption telops to specifically frame humor is frequently seen on Japanese, Korean, and Chinese TV shows (O'Hagan, 2010, p. 72). Telop (Television Opaque Projector) differs from subtitles in that it is open caption as opposed to closed caption. In other words, telops must be inserted in post-production as opposed to broadcasted live. The ramifications of this is that audiovisual telops are directly embedded into the content to add humor and entertainment, which offers more parallels with audio "laugh tracks" than normal subtitles. More importantly, telops refer to "texts inserted for purposes other than directly rendering the utterances of the locutor" (p. 73). Hence, telops in providing paratextual information for the purpose of humor open up opportunities for intervention on behalf of the viewership rather than the creator. The popularity of telops helps explain the adoption of danmu-style comments on Chinese and Japanese video portals where user interactions show little regard for the sanctity of the original content, where like telops, danmu comments often fill up the entire screen obscuring actual content. In applying this televisual concept to online sites like BiliBili, danmu culture can then be viewed as a form of "CommenTV" that provides live comments for audiovisual media, which enables "asynchronous users" to have the "synchronized views of content and add new timed comments to the content" (Hwang, Conesa, Holtzman, \& Montpetit, 2012). In doing so, it introduces new ways for user interaction that allow for instantaneous feedback which reinforces community formation and mutual collaboration. 


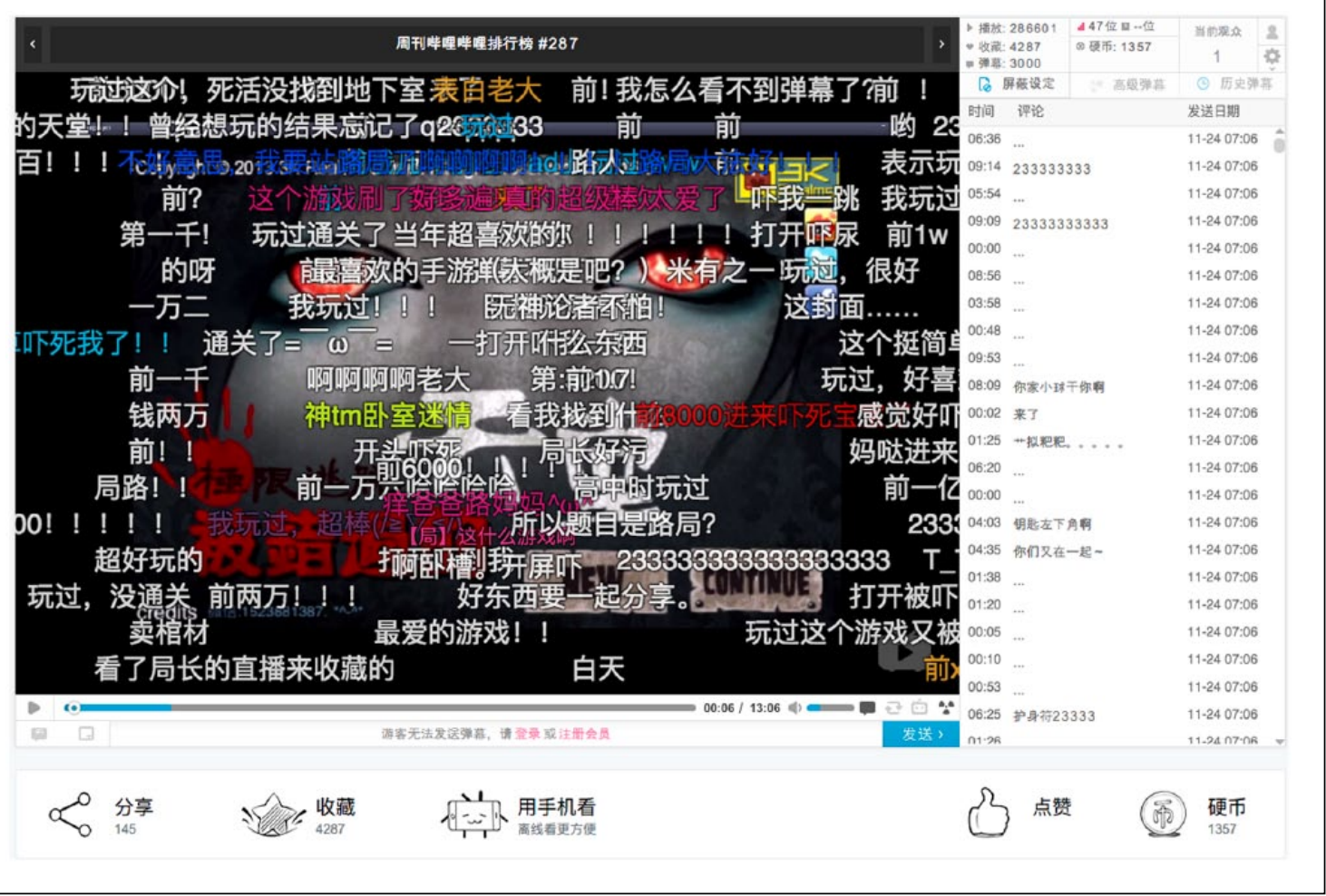

Figure 3. Example of danmu comments on BiliBili where user comments flow on top of the video instead of under it. Danmu comments can often occupy the entire screen blocking out the actual video.

CommenTV is especially relevant in the digital age with the rise of video streaming sites such as Twitch and Ustream that often place emphasis on direct user participation by promoting an active commenting culture.

\section{Danmu in the context of Chinese aesthetic tradition}

How does Chinese online culture foster such a radical system of commenting different from the West? In answering this question, we must look to traditional Chinese aesthetics that offer divergent interpretations of perspective, originality, and authorship. The imbrication of danmu comments over actual content parallels the traditional practice of tihuashi (paintings inscribed by poems) where poetry is deliberately inscribed on paintings as a form of commentary that may, or may not, be thematically related to the actual painting (Pan, 2010). Such commentary can include critiques, eulogies, notes, and personal seals that were often inscribed decades or centuries after the original artwork, which resonate with the nonsynchronous modes of online user comments that can be seen condensed in the same temporal frame despite being written years apart, constituting a false sense of liveness that defines danmu culture. While it is easy to dismiss tihuashi as mere intrusions to the original work, the symbiosis of poetry and painting in Chinese aesthetic thought signifies art as not just a static work but a living relationship between the artist and the recipient. Another key aspect of Chinese aesthetic tradition is the notion of the Chinese perspective or parallel perspective that differs from the linear perspective in Western art that favored unitary perspective based on a singular vanishing point (Hsu, 2009, p. 56). Likewise, traditional Chinese scroll art and paintings also eschew realistic 


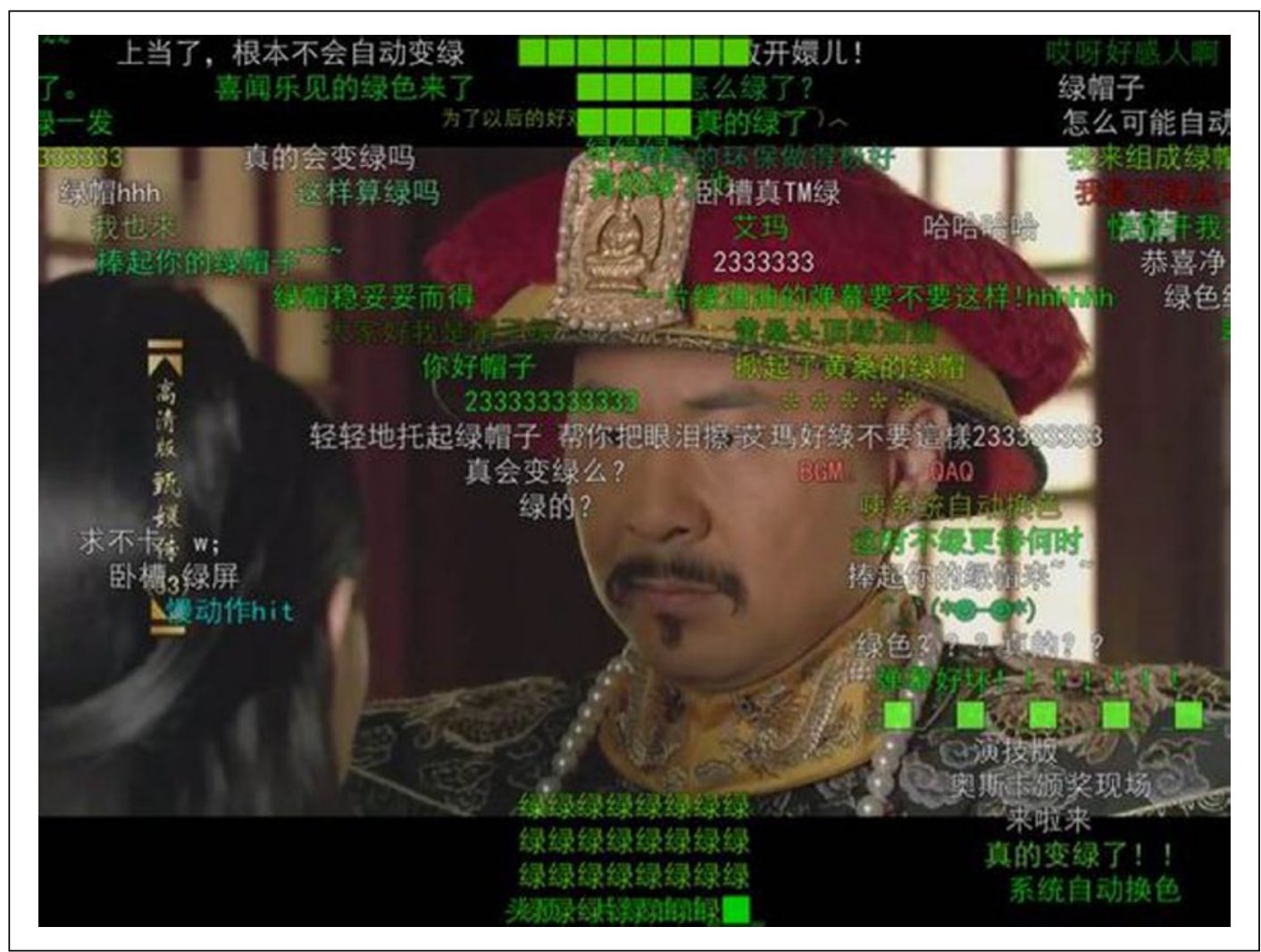

Figure 4. An example of danmu comments that uses different color fonts to convey additional information; here, green font is used as ASCll art in the form of a hat. In Chinese, wearing a green hat is a euphemism for having being cheated on, or in this case, one of the emperor's concubines had just committed adultery in the period drama "The Empress and the Palace."

depictions with that of representational expressions of reality. Western art's focus on realism based on scientific proportionality differs from the Chinese perspective that submits to the expressions of emotion. Finally, unlike the religious themes of renaissance art and the later "heroic" romanticism of early modern art, Eastern aesthetic tradition's incredulity toward the divine, the sublime, and the omnipotent reflects that "Chinese art ... is a thoroughly human and psychological one, deeply embedded in everyday reality" (Li, 2009, xvii). Understanding both the formal and the philosophical disjuncture between Eastern and Western aesthetics can help us conceptualize how cultural perceptions differ across cultures and how distinct artistic production and consumption practices can shape modern visual cultures. The Chinese perspective occupies both the formal and aesthetic elements of artistic production and consumption. Contrary to Western painting that are generally presented on a fixed canvas, "Chinese scroll painting provided a kinetic medium" (Krikke, 2000) where the viewer's perspective shifts as the scroll is unraveled. The spatial and temporal medium here is no longer confined to a single point of view, but rather the viewer is constantly interacting with multiple vantage points within the print. The departure from the Western singular perspective allows the artist to interpret works based on multiple nonlinear perspectives that operate within different temporalities. In this regard, the Chinese "hand scroll is literally a moving picture, with shifting moments and loci" (Hung, 1996, p. 59); it does not capture 
merely a moment in time but a span of time that flows with the process of unraveling.

Applying traditional aesthetic medium relates to modern digital media and online televisual consumption. Hong Kong artist and scholar Hung Keung (2013) uses the aesthetics of scroll paintings to digital arts where the traditional nonlinear perspectives "can shift the viewer's understanding of movement over time by creating an overlapping space through 'real-time' interactions." The interactivity of traditional Chinese visual aesthetics thus reflects Bakhtin's notion of aesthetics as a living activity where much like the viewing of scroll paintings, danmu comments scroll across the screen through user interaction and play. Hung's Dao project utilizes traditional shu-hua (art and calligraphy) in the form of a digitized scroll to visualize flying written characters in an interactive installation that the audience can directly participate and interact with/against. Likewise, Jan Krikke (2000) made a case for the origins of axonometric and isometric projections in ancient Chinese art as having profound influence on the spatiotemporal aspect of Western visual culture, especially in the digital age which required the projection of three-dimensional (3D) space on a two-dimensional (2D) isometric plane. Unlike linear perspectives in Western art that create depth through a single vanishing point, Chinese axonometric painting and prints are "nonhierarchical" in that subjects in both the foreground and background remain in scale to one another (Krikke, 2000). This flattening effect of axonometric art embodies multiple parallel layers that compress time and space within a singular plane (Figure 3 ). Krikke considers this method of projection as profoundly influential in digital visual culture, especially in the form of isometric gaming where the perspective scrolls across the screen on the $x$ and $y$ axis (horizontal and vertical axis), a practice similar to how we navigate the Internet as we scroll up and down a given web page. This inherently interactive nature of Chinese visual arts along with its focus on depthlessness and superficiality betrays a form of postmodern aesthetic that favors eclectic, user-driven experiences that are detached from the actual meaning or narrative of the products they are actually consuming. Hence, danmu presents the ideal case study to illustrate the multiple parallel layers of interactions that enable the reconfiguration of the temporal/spatial order contesting the unitary narrative.

\section{Postmodernism and aesthetic of hyperflatness}

Given the influence of Japanese online culture on the Chinese Internet-whether the playful culture of e'gao that originated in Japanese video game culture (Link et al., 2013, p. 95) commonly seen on Chinese BBS or the direct adoption of Nico Nico's comment system by BiliBili-comment cultures such as gailou and danmu must be understood through the lenses of Japanese cultural theory, or more specifically the perspectives of otaku culture that are prevalent on subculture sites in China. BiliBili epitomizes a distinct youth culture in China known as er'ciyuan culture or $2 \mathrm{D}$ culture. This is a direct reference to the ACG (anime, comics, and gaming) mediums that are originally produced on a flat $2 \mathrm{D}$ plane. The $2 \mathrm{D}$ culture here represents the virtual world, while the $3 \mathrm{D}$ culture (san'chiyuan) represents the real world. The emphasis on 2D aesthetics on subculture sites such as BiliBili can be attributed to the popularity of the Japanese cultural export of anime and manga that many Chinese millennials grew up with during the 1990s. This correlation between 2D and 3D planes of interactive media, specifically the dichotomy between the real and the virtual, is an important pillar of otaku culture as a whole (Saitō, 2011). While the definitions of the Chinese otaku (or zhai culture) have taken on a decidedly new meaning often overlapping with the notions of the stay-at-home loser or diaosi (Szablewicz, 2015, p. 174), the formal and aesthetic influence from Japanese anime, manga, and gaming cultures is undeniable. For example, BiliBili was originally founded as the video site Mikufans named after the anime vocaloid Hatsune Miku. Likewise, the term danmu is taken from the Japanese word danmaku (bullet curtain) that originally refers to Japanese shoot 'em up video games where bullets fill the screen in a barrage of fire much like danmu comments. Japanese cultural critic Hiroki Azuma (2009), in his rereading of Eiji Otsuka's theory of narrative consumption, proposes 
the database model of consumption to illustrate the transition away from the "tree-like" structure of modernity toward that of the multilayer "readingup" of the grand narrative. Whereas Otsuka considers narrative consumption as the "pursuit of the grand narrative" via multiple small narratives (Brienza, 2012, p. 220), for Azuma, the rise of otaku culture incorporates a generation that is increasingly disinterested in the metanarrative and instead become obsessed with multiple small narratives or so-called "nonnarratives" (p. 96). This abandonment of the grand narrative by consuming otaku emphasized the shift toward a postmodernity devoid of meaning. For Azuma, "otaku is characterized by the "rise of the media mix' in which there is no longer the linear, orderly procession of products ... rather what we find in the 'media mix' is a nonlinear and often simultaneous product loop" (p. 63). The intrusive nature of danmu comments and its disregard for the original content evince the idea of the database consumption as the metanarrative is cast away in favor of the irrelevant and the carnivalesque aspect of online comment cultures. Likewise, danmu comments operate within the coextensive plane of time and space where multimodal means of communication are produced.

Azuma specifically invoked the structure of the Internet as the embodiment of the "double-layer structure of postmodernity" in what he calls the aesthetics of "hyperflatness" (p. 97) —a term he readopted from the Japanese artistic movement known as "superflat" popularized by artist Takashi Murakami who was inspired by flat aesthetics of Japanese woodcut prints of the Edo period. The superflat directly challenges the notions of Western perspectival space where "everything is unified and hierarchized by a single vanishing point," and instead the superflat subjectivity exists purely on the surface with no relation to an origin (Looser, 2006). In applying toe superflat to the digital age, Azuma describes the Internet as a "world of differing layers in parallel" (p. 102) where the inner layer (metanarrative) loses primacy to the surface layer (nonnarrative) as users appropriate and repurpose the narrative in constructing a database where the users can call upon at any time. In other words, agency shifts to that of the consuming otaku and away from the creator as the distinction between the original and imitation are blurred. The notions of the hyperflat help conceptualize the growing popularity of er'ciyuan or two-dimensional culture in shaping youth consumption in China. Unlike the "tree-like" structure of modernity, this hyperflat model of consumption does away with the established top-down hierarchies and replaces it with the parallel coextensive forms of consumption that epitomize the aesthetics of postmodernity. Unlike Murakami who links postmodernism with Edo era consumerism, in looking at the traditional East Asian aesthetics, my intention is not to equate postmodernity with premodern Sung poetry or Ming painting, nor am I advocating the "snobbery" (Azuma, 2009, p. 66) associated with East Asian exceptionalism and nationalism. Marc Steinberg (2004) made clear that the Edo aesthetics associated with postmodern otaku culture, while not a direct temporal continuation from the premodern era, can still shed light on the "contemporary semiotic of consumption" (p. 468). In other words, the East Asian aesthetic perspective opens the possibilities to reevaluate the "regimes of signification" (Featherstone, 2007, p. 50) of how knowledge and meaning are constructed. Here, the "history of aesthetic styles displaces 'real' history" (Jameson, 1992, p. 20), the nostalgia for the past and the weakening sense of history are precisely what define the postmodern experience.

\section{Concluding remarks}

The two case studies presented here provide salient examples of the binary relationship between content and comments that creates the synthesis of information and media that coalesces to create the spaces for a new interactive medium that continues to produce, consume, and negotiate new meanings and discourses. The shifting dynamics between content and comment involve not only active participants and commenters but also new audiences in the form of lurkers and spectators who passively engage with discussions. Moreover, the popularity of comments on sites like NetEase and BiliBili divulges the increasingly visible and public nature of comments in substituting the traditional roles of media creators. 
By reorienting the temporal and spatial relationships between content and comments, as well as among comments, both gailou and danmu work to subvert the hierarchical power structures between authorship and viewership, especially in relation to the appropriation of online spaces and the reconfiguration of the temporal order by making the hidden visible. Both gailou and danmu represent new forms of everyday user-mediated online interaction within China's vibrant online landscape. However, it must be made clear that both NetEase gentie and BiliBili danmu are part of two distinct comment cultureswith the former rooted in BBS culture and the latter in online fan cultures. Despite such differences, both cases of comment cultures are indicative of the transformation of the spaces of interactions that resulted in the flattening of hierarchies between the content producers and consumers. Exploring both gailou and danmu sheds light on not only such structural shifts in online participation but, more importantly, it helps elucidate the kairotic divergence away from the metanarrative or the grand narrative. In the case of gailou culture, it is the transition toward the "live scene" of the poetic verse away from the official state narrative, while for danmu comments, it is the ruptures in the hierarchical regimes of signification through overlapping texts. Although gailou and danmu exist within separate online mediums, they operate on the same trajectory toward the disengagement from the grand narrative. Here, a new aesthetic is formed as users prioritize the process of commenting over the meaning of comments itself. In other words, the primacy of comments brings to question the authenticity of established narrative as users become obsessed with the process of consumption, as opposed to the actual content or meaning. This helps explain indifference toward the intrusive nature of danmu comments that often block off the actual content where net users disavow the need for the metanarrative. Here, the surface layers of interaction (comments) are prioritized over the inner layers of meaning (content) where each succeeding layer of comments produces its own meanings without being fixed to a singular narrative. Both the building up (gailou) and the layering of content (danmu) underscore the changing attitudes of Chinese net users in navigating digital spaces and how new subjectivities are created through the destabilization of the established order. If gailou culture can be classified as the building up of narrative via multiple small narratives, then danmu culture can be seen as not only the direct subversion of the metanarrative but the very nascency of the Chinese postmodern consciousness.

\section{Note}

1. I use the term net user and netizen interchangeably; granted netizens are more frequently used in the Chinese context.

\section{References}

Azuma, H. (2009). Otaku: Japan's database animals. (J.E. Abel \& S. Kono, Trans.). Minneapolis: University of Minnesota Press.

Bakhtin, M. M., Holquist, M., \& Liapunov, V. (1990). Art and answerability: Early philosophical essays (Vol. 9). Austin: University of Texas Press.

Brienza, C. (2012). Taking otaku theory overseas: Comics studies and Japan's theorists of postmodern cultural consumption. Studies in Comics, 3, 213-229.

Cai, X. A. (2015). Fansubbing humor: A mainland China case study. Journalism and Mass Communication, 5 , 435-453.

Chakrabarty, D. (2009). Provincializing Europe: Postcolonial thought and historical difference. Princeton: Princeton University Press. (Original work published 2000)

Diaz-Cintas, J. D., \& Sánchez, P. M. (2006). Fansubs: Audiovisual translation in an amateur environment. The Journal of Specialised Translation, 6, 37-52.

Dirlik, A., \& Zhang, X. (2000). Introduction: Postmodernism and China. In A. Dirlik \& X. Zhang (Eds.), Postmodernism and China (pp. 1-16). Durham, NC: Duke University Press.

Featherstone, M. (2007). Consumer culture and postmodernism (2nd ed.). London, England: SAGE.

Fiske, J. (2010). Understanding popular culture. New York, NY: Routledge. (Original work published 1989)

Gong, H., \& Yang, X. (2010). Digitized parody: The politics of egao in contemporary China. China Information, 24, 3-26.

Grossman, L. (2006, December 25). You-Yes, youAre TIME's person of the year. TIME Magazine, Retrieved from http://content.time.com/time/magazine/article $/ 0,9171,1570810,00 . \mathrm{html}$

Guo, L. (2012). Collaborative efforts: An exploratory study of citizen media in China. Global Media and Communication, 8, 135-155. 
Harvey, D. (1989). The conditions of postmodernity: An enquiry into the origins of cultural change. New York, NY: Blackwell.

Hawes, C. S. (2006). The social circulation of poetry in the mid-Northern Song: Emotional energy and literati self-cultivation. Albany, NY: SUNY Press.

Holtz, P., Kronberger, N., \& Wagner, W. (2012). Analyzing internet forums: A practical guide. Journal of Media Psychology, 24, 55-66.

Horowitz, B. (2015, July 27). Everything in its right place. Retrieved from https://googleblog.blogspot. co.uk/2015/07/everything-in-its-right-place.html

Hsu, H. M. A. (2009). Structured perceptions of real and imagined landscapes in early China. In K. Raaflaub \& R. Talbert (Eds.), Geography and ethnography: Perceptions of the world in pre-modern societies (pp. 44-45). Hoboken, NJ: John Wiley \& Sons.

Hung, C. F. (2006). The politics of cyber participation in the PRC: The implications of contingency for the awareness of citizens' rights. Issues \& Studies, 42, 137.

Hung, W. W. (1996). The double screen: Medium and representation in Chinese painting. London, England: Reaktion Books.

Hwang, J. Y., Conesa, P. P., Holtzman, H., \& Montpetit, M. J. (2012). CommenTV: A time-sensitive social commenting system for audiovisual content. In Consumer Communications and Networking Conference (CCNC) (pp. 84-88). New York, NY: IEEE.

Inwood, H. (2014). Verse going viral: China's new media scenes. Seattle: University of Washington Press.

Jameson, F. (1992). Postmodernism, or, the cultural logic of late capitalism. Durham, NC: Duke University Press.

Jenkins, H. (2006a). Convergence culture: Where old and new media collide. New York: New York University Press.

Jenkins, H. (2006b). Fans, bloggers, and gamers: Exploring participatory culture. New York: New York University Press.

Jenkins, H. (2012c). Textual poachers: Television fans and participatory culture. New York, NY: Routledge.

Jiang, Z. (2010, January). 10 nian 100 ge rang shenhuo gen meihao de dongxi (" 100 best things in life of the past decade"). Southern People's Weekly, 2, 22-41.

Keen, A. (2008). The cult of the amateur: How blogs, MySpace, YouTube, and the rest of today's usergenerated media are destroying our economy, our culture, and our values. Chicago, IL: Broadway Business.

Keung, H. (2013). How the traditional Chinese concept of time and space can be applied through digital moving images. Typography Day. Retrieved from http:// www.typoday.in/2013/spk papers13/hung-keungtypographyday2013.pdf
Krikke, J. (2000). Axonometry: A matter of perspective. IEEE Computer Graphics and Applications, 20, $7-11$

Lévy, P. (1997). Collective intelligence. Cambridge, MA: Perseus Books.

Li, H. (2011). Parody and Resistance on the Chinese Internet. In D. K. Herold \& P. Marolt (Eds.), Online society in China: Creating, celebrating, and instrumentalizing the online carnival (pp. 71-88). New York, NY: Routledge.

Li, Z. (2009). The Chinese aesthetic tradition. Honolulu: University of Hawaii Press.

Link, P., Madsen, R. P., \& Pickowicz, P. G. (Eds.). (2013). Restless China. Lanham, MD: Rowman \& Littlefield.

Link, P., \& Zhou, K. (2001). Shunkouliu: Popular satirical sayings and popular thought. In R. Madsen, P. Link, \& P. Pickowicz (Eds.), Popular China: Unofficial culture in a globalizing society (pp. 89-110). Lanham, MD: Rowman \& Littlefield Publishers.

Liu, J. J. (1966). The art of Chinese poetry. Chicago, IL: University of Chicago Press.

Looser, T. (2006). Superflat and the layers of image and history in 1990s Japan. Mechademia, 1(1), 92-109.

Lyotard, J. F. (1984). The postmodern condition: A report on knowledge (Vol. 10). Minneapolis, MN: University of Minnesota Press.

MacKinnon, R. (2008). Flatter world and thicker walls? Blogs, censorship and civic discourse in China. Public Choice, 134, 31-46.

Maffesoli, M. (1996). The time of the tribes: The decline of individualism in mass society (Vol. 41). London, England: SAGE.

Meng, B. (2011). From steamed bun to grass mud horse: E Gao as alternative political discourse on the Chinese Internet. Global Media and Communication, 7, 33-51.

NetEase. (2015). gentie. (NetEase comments). Retrieved from http://tie.163.com/gt/special/ending2015/

O'Hagan, M. (2010). Japanese TV entertainment: Framing humour with open caption telop. In D. Chiaro (Ed.), Translation, humor and the media (pp. 70-88). London, England: Bloomsbury Publishing.

Pan, D. (2010). The lyrical resonance between Chinese poets and painters: The tradition and poetics of Tihuashi. Amherst, NY: Cambria Press.

Phillips, W. (2015). This is why we can't have nice things: Mapping the relationship between online trolling and mainstream culture. Chicago, MA: The MIT Press.

Qian, S. (2015, July). B zhan liu nian shu ju: Xiao xue shen bu duo yong hu pian hao ri ju 66 years of user data on B station: Very little primary school students, 
users enjoy Japanese dramas, anime, and Kitchku]. Tencent News. Retrieved from http://games. qq.com/a/20151117/047220.htm

Qiang, X. (2011). The battle for the Chinese Internet. Journal of Democracy, 22, 47-61.

Qin, A. (2014). Theaters in China screen movies, and views' text messages. The New York Times. Retrieved from http://sinosphere.blogs.nytimes. com/2014/08/20/theaters-in-china-screen-moviesand-viewers-text-messages/? $\mathrm{r}=0$

Reagle, J. M. (2015). Reading the comments: Likers, haters, and manipulators at the bottom of the Web. Cambridge, MA: The MIT Press.

Saitō, T. (2011). Beautiful fighting girl. Minneapolis: University of Minnesota Press.

Scott, J. C. (1990). Domination and the arts of resistance: Hidden transcripts. New Haven, CT: Yale University Press.

Shuang, F. (2015). Sub-culture redefines online investments. Shanghai Daily. Retrieved from http://www. ecns.cn/business/2015/11-26/190227.shtml

Steinberg, M. (2004). Otaku consumption, superflat art and the return to Edo. Japan Forum, 16, 449-471.

Szablewicz, M. (2015). The "losers" of China's internet: Memes as "Structures of Feeling" for disillusioned young netizens. In G. Yang (Ed.), China's contested internet (pp. 168-191). Copenhagen, Denmark: NIAS Press.

Tapscott, D., \& Williams, A. D. (2008). Wikinomics: How mass collaboration changes everything. New York, NY: Penguin Books.
Thornton, P. M. (2002a). Framing dissent in contemporary China: Irony, ambiguity and metonymy. The China Quarterly, 171, 661-681.

Thornton, P. M. (2002b). Insinuation, insult, and invective: The threshold of power and protest in modern China. Comparative Studies in Society and History, 44, 597-619.

Tong, Q. S., \& Zhou, X. (2002). Criticism and society: The birth of the modern critical subject in China. Boundary 2, 29, 153-176

Williams, R. (1958). Culture and society, 1780-1950. New York, NY: Anchor Books.

Yang, G. (2009). The power of the internet in China: Citizen activism online. New York, NY: Columbia University Press.

Yang, K. C. (2011). The Aborted Green Dam youth escort censor-ware project in China: A case study of emerging civic participation in China's internet policy-making process. Telematics and Informatics, 28, 101-111.

\section{Author biography}

Yizhou Xu is a Doctoral Candidate in Media and Cultural Studies at Department of Communication Arts at the University of Wisconsin-Madison. Yizhou completed his undergraduate studies at Bucknell University with degrees in History and International Relations. His research interests lie in digital media consumption among urban migrant youths in China. Prior to academia, Yizhou was a journalist and documentary producer based in Beijing, working for news outlets such as NPR and CBS News. 